\title{
Delayed Pneumatosis Intestinalis Induced by Blunt Trauma in a Strangulated Small Intestine
}

\author{
Dongsub Noh, M.D.*, Hyun Min Cho, M.D., Ph.D. ${ }^{\dagger}$, Chan-Kyu Lee, M.D. ${ }^{\dagger}$, \\ Seon Hee Kim, M.D. ${ }^{\dagger}$, Kwang Hee Yeo, M.D. \\ *Department of Trauma Surgery, Eulji University Hospital, Daejeon, \\ ${ }^{\dagger}$ Division of Truma Surgery, Pusan National University Hospital, Busan, Korea
}

\author{
Correspondence to: \\ Kwang Hee Yeo, M.D. \\ Division of Truma Surgery, \\ Pusan National University \\ Hospital, 179 Gudeok-ro, \\ Seo-gu, Busan 49241, Korea \\ Tel: +82-51-240-7369 \\ Fax: +82-51-240-7719 \\ E-mail: songyu0428@gmail.com
}

An ischemia-reperfusion injury of the intestine due to blunt trauma is very rare. Low blood flow can result in an incarceration and an ischemia-reperfusion injury of the small intestine. A 63-year-old woman fell, producing a splenic rupture. Despite the successful angio-embolization of the splenic rupture, the patient continued to suffer from hypotension. During laparotomy to identify the bowel injury, no intestinal perforation was found. However, we found a hemorrhagic infarction of the small intestine with congestion of the submucosal blood vessels. The part of bowel with the hemorrhagic infarction was resected and reconstructed with a jejuno-colic anastomosis. After surgery, she recovered from the trauma and was discharged without complications. We present this ischemia-reperfusion injury of the intestine due to blunt trauma. Meticulous examination and computed tomography scan is mandatory for diagnosis and assessment of treatment outcome. (J Acute Care Surg 2017;7:83-86)

Key Words: Blunt trauma, Pneumatosis intestinalis, Strangulation, Fall down, Small bowel

Received April 11, 2017, Accepted June 24, 2017

Copyright $($ C 2017 by Korean Society of Acute Care Surgery

(c) This is an Open Access article distributed under the terms of the Creative Commons Attribution Non-Commercial License (http://creativecommons.org/licenses/by-nc/4.0) which permits unrestricted non-commercial use, distribution, and reproduction in any medium, provided the original work is properly cited.

\section{Introduction}

Pneumatosis intestinalis is an imaging phenomenon representing the presence of gas in the bowel wall. Low blood pressure and low blood flow led to the incarceration of the bowel. During reperfusion, the incarcerated bowel became edematous and caused tissue damage. The gas-producing bacteria had entered the bowel wall through the break point of intestinal integrity. Bowel and bladder injuries have been observed in less than $1 \%$ of these falling injuries [1]. We experienced this Pneumatosis intestinalis after falling down trauma. This article focuses on symptoms, diagnosis and treatment of this life-threatening condition based on a case report and review of the literature.

\section{Case Report}

A 63-year-old female slipped and fell from an approximately $40 \mathrm{~m}$ height from her apartment. She had a hysterectomy due to myoma 24 years prior, and took medication for hypertension. She did not have any signs or symptoms of an acute surgical abdomen or abnormal digestive function. Upon arriving at our hospital, her systolic blood pressure was less than $60 \mathrm{mmHg}$, and her pulse rate was 130 beats/min. There were many contusions on her back, but no definite contusion on her 


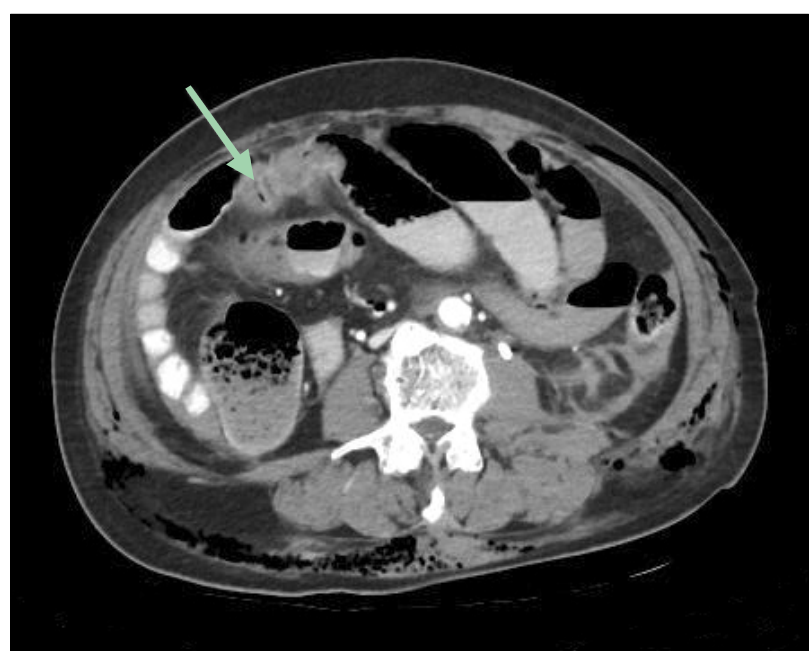

Fig. 1. Follow-up computed tomography scan revealed a completely infarcted splenic artery. But the small intestine was swollen, and there was an air shadow in the small intestinal wall (arrow).

abdomen. After resuscitation, the computed tomography (CT) scan revealed a splenic rupture and multiple bilateral rear rib fractures, but there was no definite injury of her abdominal solid organs or intestine other than the spleen. The splenic rupture was treated with angioembolization. After the angioembolization, her blood pressure returned to $120 / 80 \mathrm{mmHg}$.

Six hours after the angioembolization, her blood pressure had decreased to $70 / 60 \mathrm{mmHg}$, and her hemoglobin levels declined from 12.2 to $7.5 \mathrm{~g} / \mathrm{dl}$. On physical examination, her abdomen was distended. A follow-up CT scan showed a completely infarcted splenic artery. The small intestine was also swollen, and there was an air shadow in the small intestine (Fig. 1). An exploratory laparotomy was planned for the identification of the bowel injury. A median laparotomy was performed, and the abdominal cavity was examined. The small intestine adhered to the abdominal wall, and the small intestine had herniated through adhesion bands created due to the previous operation. After adhesiolysis, there was no definite perforation or contusion on the small intestine, but the small intestine was incarcerated from $100 \mathrm{~cm}$ below the Treitz ligament to $10 \mathrm{~cm}$ above the ileocecal valve (Fig. 2). There was only one point of fibrotic adhesion to the abdominal wall. The incarcerated intestine was resected, and the remaining parts of the small intestine were anastomosed in an end-to-end fashion (jejuno-colic anastomosis). The pathologic findings revealed a

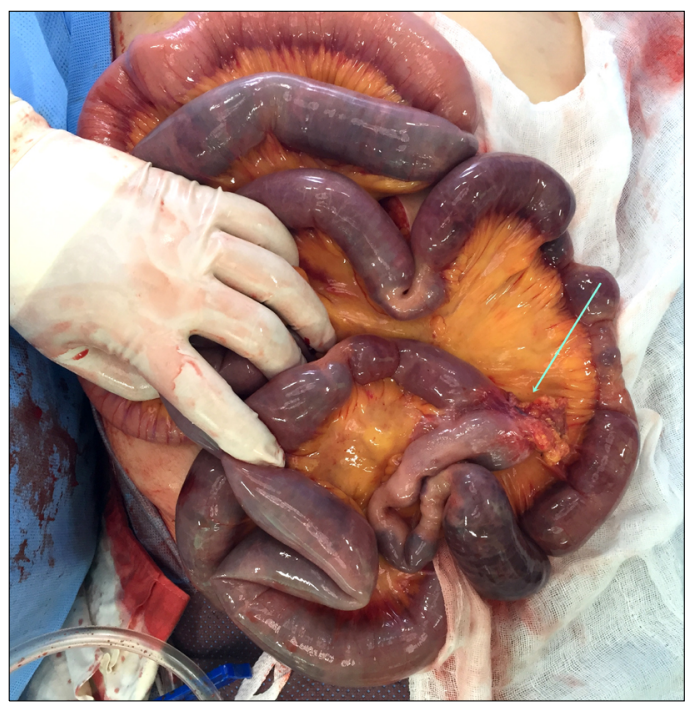

Fig. 2. There was no definite perforation or contusion of the small intestine, but the small intestine was incarcerated from below 100 $\mathrm{cm}$ in Treitz ligament to upper $10 \mathrm{~cm}$ in ilececal valve. There was only one point of fibrotic adhesion to the abdominal wall (arrow).

hemorrhagic infarction of the small intestine with the congestion of submucosal blood vessels and multiple foci of necrotic changes with thin walls. After surgery, she gradually tolerated oral feedings and was discharged from the hospital without any complications.

\section{Discussion}

We have reported on a very rare case of an ischemia-reperfusion injury of the small intestine (pneumatosis intestinalis) due to blunt trauma. Few patients who have fallen from heights have intraabdominal injuries, with the majority requiring operative or angioembolization management for injuries to solid organs. However, bowel and bladder injuries have been observed in less than $1 \%$ of these falling injuries [1]. We thought the splenic injury caused the low blood pressure, which could lead to an ischemic intestine injury. After a successful angioembolization, the restored blood pressure levels could cause a reperfusion injury in the strangulated intestine due to the previous operative fibrosis in the abdominal cavity. It took around 10 hours to find this pneumatosis intestinalis on a CT scan. Otherwise, the plain film radiographs of the chest and abdomen at the time of the initial presentation were normal.

Pneumatosis intestinalis is an imaging phenomenon representing 
the presence of gas in the bowel wall. The suggested mechanism of pneumatosis intestinalis is secondary to the gas-producing bacteria that enter the bowel wall when the circulation is compromised [2]. This gas cannot transgress all three layers of the bowel wall, and pneumoperitoneum is not consistently present [3]. Intra-abdominal adhesions are the first cause of small bowel obstructions, strangulation, and ischemia [4]. In this case, the patient had no specific signs or symptoms of an internal hernia after her hysterectomy. The splenic injury caused the low blood pressure, and this low blood pressure may have led to an ischemic injury of the intestine (pneumatosis intestinalis).

Shock, vascular surgery, and small bowel transplantation are clinical conditions that are associated with mesenteric ischemiareperfusion injury [4]. The interruption of the blood supply results in ischemic injury that rapidly damages metabolically active tissues [5]. Paradoxically, restoration of blood flow to the ischemic tissue initiates a cascade of events that may lead to additional cellular injury known as reperfusion injury [6]. Ischemia-reperfusion injury can result in tissue damage caused by the generation of oxygen free radicals, neutrophilic infiltration, and mucosal apoptosis [5]. Among all internal organs, the intestine is probably the most sensitive to ischemia-reperfusion injury [5]. The reduction of blood supply results in damage to the intestinal mucosa [6]. Enterocytes that are located at the tips of the villi are very sensitive to the effects of ischemia [6]. Gas-producing bacteria enter the bowel wall when the circulation is compromised [2]. Therefore, pneumatosis intestinalis can occur during these circumstances. Although there was already an internal hernia, she had no signs or symptoms due to the maintenance of essential blood flow to the herniated bowel in this case. However, low blood pressure and low blood flow led to the incarceration of the herniated bowel. During reperfusion, the incarcerated bowel became edematous and caused tissue damage. The gas-producing bacteria had entered the bowel wall through the break point of intestinal integrity. The pathologic finding of a hemorrhagic infarction of the small intestine with congestion of the submucosal blood vessels and multiple foci of necrotic changes and thin walls might support the diagnosis of ischemia-reperfusion injury. Pneumatosis intestinalis in the patient with blunt abdominal trauma increase the clinician's concerns about the occurrence of rapidly fatal, but potentially correctable conditions, such as bowel ischemia and/or necrosis [3]. Subsequently, in those cases, the recovery of the patient is delayed, morbidity is increased, and multiple organ failures occur [6]. Fortunately, we found this injury early due to the decrease in blood pressure and hemoglobin levels. An early repeat CT scan was able to find this ischemia-reperfusion injury due to the decreased blood flow and hemoglobin levels.

Prior to this case, an ischemia-reperfusion injury of the intestine due to blunt trauma had not yet been reported. We present this case of ischemia-reperfusion injury of the intestine due to blunt trauma. Meticulous examination and abdominal follow up CT scan must be needed for patient who had prior abdominal surgery and symptoms of intermittent ileus.

\section{Acknowledgments}

This work was supported by clinical research grant from Pusan National University Hospital in 2017.

\section{Conflicts of Interest}

No potential conflict of interest relevant to this article was reported.

\section{References}

1. Velmahos GC, Demetriades D, Theodorou D, Cornwell EE 3rd, Belzberg $\mathrm{H}$, Asensio J, et al. Patterns of injury in victims of urban free-falls. World J Surg 1997;21:816-20.

2. Ellis LM, Bland KI, Copeland EM. Benign and premalignant lesions of the colon and rectum. In: Moody FG, Carey LC, Jones RS, Kelly KA, Nahrwold DL, Skinner DB. Surgical treatment of digestive disease. 2nd ed. Chicago: Yearbook Medical Publishers; 1990. p.770-98.

3. Price RE. The plain film of the abdomen. In: Taveras JM, Ferrucci JT. Radiology. Philadelphia: JB Lippincott; 1995. p.1-21.

4. Catena F, Di Saverio S, Coccolini F, Ansaloni L, De Simone B, Sartelli M, et al. Adhesive small bowel adhesions obstruction: Evolutions in diagnosis, management and prevention. World J Gastrointest Surg 2016;8:222-31.

5. Chu W, Li S, Wang S, Yan A, Nie L. Ischemic postconditioning provides protection against ischemia-reperfusion injury in intestines of rats. Int J Clin Exp Pathol 2015;8: 6474-81. 
6. Mallick IH, Yang W, Winslet MC, Seifalian AM. Ischemia-reperfusion injury of the intestine and protective strategies against injury. Dig Dis Sci 2004;49:1359-77. 